\title{
Use of specific immunoradiometric assay to determine preterm neonatal insulin-glucose relations
}

\author{
J M Hawdon, M Hubbard, C N Hales, P M S Clark
}

\begin{abstract}
Highly specific immunoradiometric assays were used to measure plasma concentrations of insulin, proinsulin, and 32-33 split proinsulin in neonates $(n=16)$. Neonatal plasma insulin concentrations were high relative to blood glucose concentrations and compared with adult insulin-glucose relations. Concentrations of proinsulin and 32-33 split proinsulin together accounted for $34-70 \%$ of the total concentration of insulin and pro-peptides.

This study confirms the need to use a specific assay and neonatal reference data in the diagnosis of neonatal hyperinsulinism, and shows that neonatal pancreatic $\beta$ cell function may differ from that of older subjects.

(Arch Dis Child 1995; 73: F166-F169)
\end{abstract}

Keywords: insulin, proinsulin, pancreas.

It has recently been shown that neonatal glucose-insulin relations differ from those of older children. ${ }^{1}$ There was probably a full crossreaction of proinsulin and other insulin propeptides with insulin in the double antibody radioimmunoassay ${ }^{2}$ used in this study. ${ }^{1}$ Proinsulin is present in considerable amounts in cord plasma samples. ${ }^{34}$ However, it is not known whether concentrations diminish with postnatal age or vary with gestational age, and no previous study has measured the separate concentrations of proinsulin and partially processed proinsulin in neonates. This study aimed to use highly specific immunoradiometric assays (IRMAs) to measure separately the concentrations of insulin, proinsulin, and 32-33 split proinsulin to determine their concentrations in neonatal plasma, and to investigate whether the apparent hyperinsulinaemia previously shown in neonates was related to the overestimation of plasma insulin concentrations. ${ }^{1}$

Institute of Child Health, Liverpool University

J M Hawdon

Neonatal Unit, Liverpool Maternity Hospital

$M$ Hubbard

Department of Clinical Biochemistry,

Addenbrooke's

Hospital, Cambridge

C N Hales,

P M S Clark

Correspondence to:

Dr J M Hawdon, Neonatal Unit, Obstetric Hospital, University College London Hospitals, Huntley Street, London WC1A 6AU.

Accepted 24 July 1995

\section{Methods}

As serial samples were required to investigate the effect of postnatal age on insulin and insulin pro-peptide concentrations, the subjects of the study were a group of preterm neonates who were nursed on a neonatal unit and who required regular blood sampling for clinical purposes. It was not possible to study entirely healthy term babies because of the number and volume of the samples required. However, infants of diabetic mothers, small for gestational age babies, and babies who were seriously unwell (hypoxic, acidotic, hypotensive or infected) were excluded. For as many babies as possible, samples were taken from the umbilical cord at birth, and then venous or arterial samples were collected daily for the first postnatal week. Up to $1 \mathrm{ml}$ of blood was taken on each occasion, samples were centrifuged immediately, and the supernatant plasma was frozen.

Blood for assay of glucose concentrations was collected and assayed by microenzymatic methods, as described before. ${ }^{1}$

Plasma concentrations of insulin, proinsulin, and 32-33 split proinsulin were measured by two site immunoradiometric assays (IRMA). ${ }^{5}$ The insulin assay was calibrated against the first International Reference Preparation 66/304 National Institute of Biological Standards and Controls, Potters Bar, England) and had an interassay coefficient of variation of less than $12 \%$ over the concentration range 27-341 pmol/l. The intact proinsulin and 32-33 split proinsulin assays were calibrated against synthetic peptides (Lilly Research Laboratories, Indianapolis, USA) and had interassay coefficients of variation of less than $13 \%$ over the concentration ranges of 3.8-65 $\mathrm{pmol} / /$ and $6 \cdot 4-65 \mathrm{pmol} / \mathrm{l}$, respectively.

SPSS-PC was used for statistical analysis, using logarithmic transformation of insulin, proinsulin and 32-33 split proinsulin concentrations for all calculations and analysis. Multiple regression analysis was performed to examine the separate correlations between independent variables such as postnatal and gestational age on plasma insulin and insulin propeptide concentrations.

Ethical approval for the study was granted Children's Hospital Alder Hey Trust.

Table 1 Concentrations (median/range) of insulin and propeptide molecules in first postnatal week

\begin{tabular}{|c|c|c|c|c|c|c|c|c|}
\hline Age & $\begin{array}{l}\text { Insu } \\
n=\end{array}$ & in & $\begin{array}{l}\text { Proi } \\
n=\end{array}$ & $\begin{array}{l}\text { asulin } \\
\text { (pmoll) }\end{array}$ & $\begin{array}{l}32- \\
n=\end{array}$ & $\begin{array}{l}3 \text { Split } \\
\text { (pmoll) }\end{array}$ & $\begin{array}{l}\text { Ins:total } \\
\text { (\%) }\end{array}$ & $\begin{array}{l}\text { Pro:ins } \\
\text { (\%) }\end{array}$ \\
\hline $\begin{array}{l}\text { Cord } \\
<12 \text { Hours } \\
12-24 \text { Hours } \\
\text { Day } 2 \\
\text { Day } 3 \\
\text { Day } 4 \\
\text { Day } 5 \\
\text { Day } 6 \\
\text { 0-6 Days }\end{array}$ & $\begin{array}{r}9 \\
13 \\
12 \\
9 \\
15 \\
9 \\
8 \\
11 \\
86\end{array}$ & $\begin{array}{l}(64)(8-166) \\
(50)(8-133) \\
(46)(11-122) \\
(52)(17-178) \\
(29)(13-192) \\
(52)(5-199) \\
(52)(13-191) \\
(57)(33-111) \\
(50)(5-199)\end{array}$ & $\begin{array}{r}9 \\
12 \\
9 \\
10 \\
13 \\
9 \\
9 \\
9 \\
80\end{array}$ & $\begin{array}{l}(12)(8-24) \\
(14)(9-17) \\
(14)(7-87) \\
(12)(5-21) \\
(10)(4-30) \\
(8)(4-17) \\
(8)(5-10) \\
(10)(5-13) \\
(11)(4-87)\end{array}$ & $\begin{array}{r}5 \\
5 \\
4 \\
2 \\
3 \\
1 \\
1 \\
3 \\
24\end{array}$ & $\begin{array}{l}(35)(12-44) \\
(16)(10-20) \\
(15)(12-22) \\
(15)(11-18) \\
(9)(1-25) \\
(19) \\
(32) \\
(27)(13-41) \\
(19)(1-44)\end{array}$ & $\begin{array}{l}38(35-49) \\
46(32-47) \\
35(29-47) \\
46(43-49) \\
55(43-66) \\
49 \\
45 \\
42(39-49) \\
43(30-66)\end{array}$ & $\begin{array}{l}73(49-100) \\
66(50-133) \\
79(43-147) \\
59(40-102) \\
68(45-106) \\
45(31-154) \\
49(40-63) \\
50(41-64) \\
66(31-95)\end{array}$ \\
\hline
\end{tabular}




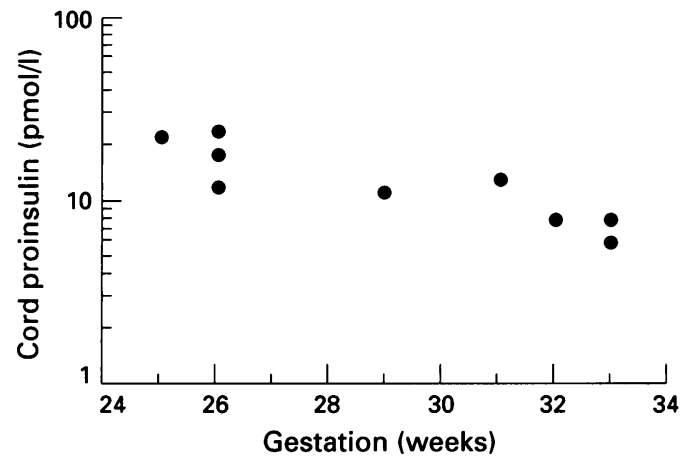

Figure 1 Correlation between proinsulin concentration and gestation.

\section{Results}

Eighty six samples were taken from 16 neonates who were less than 7 days old. In some cases there was insufficient plasma to measure the concentration of all three molecules and in these cases insulin measurement was the priority. The number of samples obtained for each postnatal day is shown in table 1 . The median gestation was 29 weeks (range 25-34 weeks) and the median birthweight was $1459 \mathrm{~g}$ (range 666-2400 g).

The concentrations of insulin, proinsulin, and 32-33 split proinsulin and the percentages of insulin/(insulin + proinsulin +32-33 split proinsulin) (ins:total) and proinsulin/insulin (proins:ins) are shown in table 1. Plasma concentrations of insulin (5-199 pmol/1), proinsulin (4-87 pmol/1), and 32-33 split proinsulin $(1-44 \mathrm{pmol} / \mathrm{l})$ varied widely. The ins:total ratio varied from $30-66 \%$; this narrower range may reflect the fact that infants with high insulin concentrations also had high concentrations of proinsulin and 32-33 split proinsulin. These data suggest that a radioimmunoassay which does not differentiate between insulin and insulin propeptides may overestimate plasma insulin concentrations by 34-70\%. Proins:ins varied from 31-154\%.

Cord and postnatal plasma insulin and 32-33 split proinsulin concentrations and the ins:total and proins:ins ratios did not correlate with birthweight, gestational age, nor birthweight standard deviation score. Cord proinsulin concentrations were not related to birthweight nor birthweight SD score, but there was a negative correlation between each infant's cord plasma proinsulin concentration

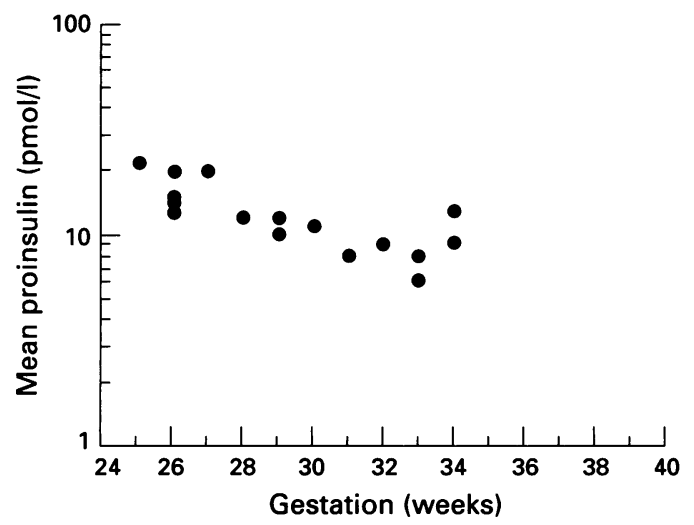

Figure 2 Correlation between mean proinsulin concentration and gestation.

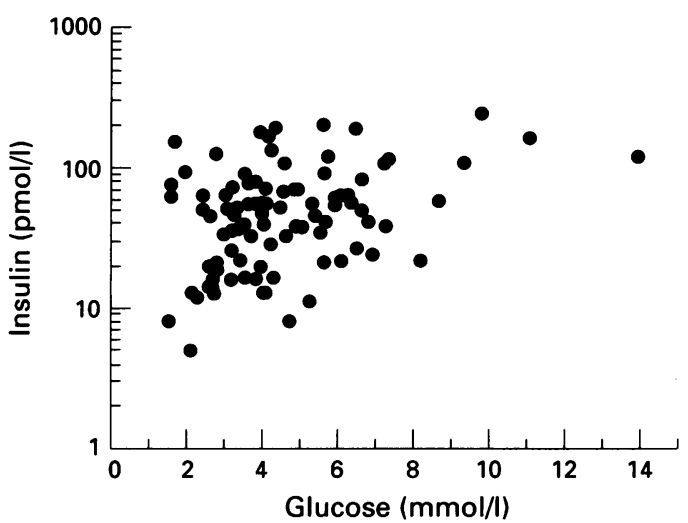

Figure 3 Insulin:glucose association in preterm (non-IDM) neonates.

and gestational age $(\mathrm{r}=-0.84, \mathrm{P}<0.01)$ (fig 1$)$. Each baby's mean postnatal plasma proinsulin also correlated with gestational age $(r=-0 \cdot 78$, $\mathrm{P}<0.01$ ) (fig 2).

Considering all data points for all infants together, there was a positive correlation between plasma insulin and blood glucose concentrations $(r=0.29, P<0.01)$ (fig 3$)$, but at each blood glucose concentration, plasma insulin concentrations varied widely and many babies with low blood glucose had high plasma insulin concentrations. Furthermore, when each infant's insulin:glucose relation was examined this was found to vary widely both within and between individual subjects (table 2 ). Only one of the 16 neonates had the expected positive insulin:glucose association which achieved significance $(r=0.99$, $P<0.001$ ) (fig 4).

Plasma proinsulin and 32-33 split proinsulin concentrations did not correlate with blood glucose concentration.

Plasma insulin and 32-33 split proinsulin concentrations and ins:total did not correlate with postnatal age. Considering all data points for all infants together, there was a negative correlation between plasma proinsulin concentration and postnatal age $(\mathrm{r}=-0.45, \mathrm{P}<0.001)$ (fig 5). When each infant was considered separately, however, only one had a significant correlation between proinsulin and postnatal age $(r=-0.94, P<0.01)$ (fig 6$)$, and this baby also had a significant insulin:glucose correlation (see above).

Insulin, proinsulin, and 32-33 split proinsulin concentrations were not related to the

Table 2 Mean (95\% CI) $\log _{10}$ insulin: glucose ratios for each infant who had at least four measurements

\begin{tabular}{lll}
\hline Case No & Mean Ig insulin:glucose & $95 \% \mathrm{CI}$ \\
\hline 1 & $0 \cdot 30$ & $0 \cdot 20-0.60$ \\
$2^{\star}$ & $0 \cdot 34$ & $0 \cdot 28-0.40$ \\
3 & $0 \cdot 37$ & $0 \cdot 27-0.47$ \\
4 & $0 \cdot 40$ & $0 \cdot 26-0.54$ \\
5 & $0 \cdot 39$ & $0 \cdot 33-0.45$ \\
6 & $0 \cdot 27$ & $0 \cdot 13-0.41$ \\
7 & $0 \cdot 49$ & $0 \cdot 13-0.85$ \\
8 & 0.32 & $0 \cdot 24-0.40$ \\
9 & 0.37 & $0 \cdot 27-0.42$ \\
10 & 0.59 & $0.51-0.67$ \\
11 & 0.51 & $0 \cdot 45-0.57$ \\
12 & 0.54 & $0.42-0.66$ \\
13 & 0.58 & $0.32-0.84$ \\
Mean of all infants' means & 0.42 & $0.36-0.48$
\end{tabular}

*Infant whose data are plotted in figs 4 and 6. 


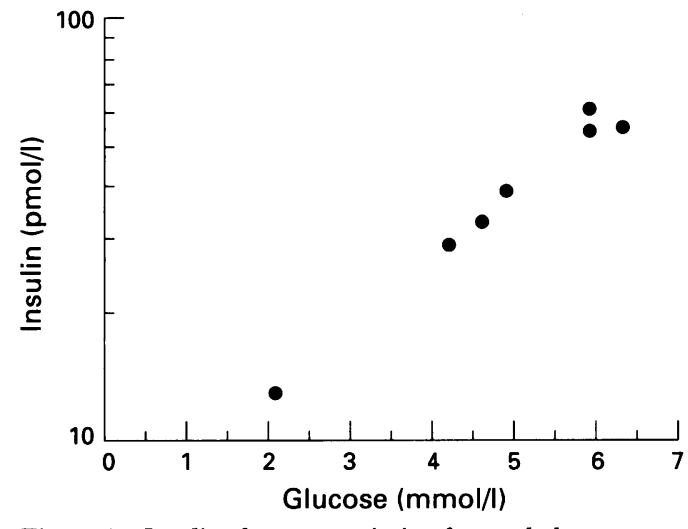

Figure 4 Insulin:glucose association for one baby.

rate of intravenous glucose infusion nor daily milk intake.

\section{Discussion}

The data presented here have several clinical implications. First, this study shows that proinsulin and 32-33 split proinsulin are present in considerable concentrations in preterm neonatal plasma, even after birth. Our findings agree with those of previous studies which found that proinsulin accounted for $29-100 \%$ of immunoreactive insulin in cord blood of normal infants, ${ }^{23}$ but we have also provided further information for the postnatal period. These previous studies did not differentiate between proinsulin and split proinsulins. The use of a non-specific assay which allows crossreaction of other molecules with insulin will overestimate insulin concentrations to a variable and unpredictable degree (our data suggest this overestimation may range from $34-70 \%$ ). This may result in the erroneous diagnosis of neonatal hyperinsulinism. We recommend that a highly specific assay should be used when carrying out neonatal endocrinological investigations.

The second clinical implication is that, even when a highly specific assay is used and there is no overestimation of insulin concentration, neonatal insulin:glucose ratios differ from those of older children, this is in agreement with the previous study. ${ }^{1}$ At equivalent blood glucose concentrations, neonatal insulin concentrations are higher than those found in older children and only one infant had the expected positive insulin:glucose ratio. ${ }^{1}$ The

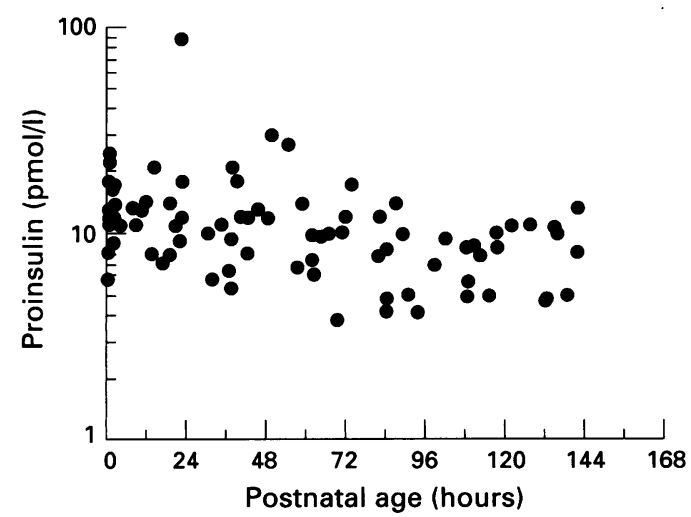

Figure 5 Correlation between proinsulin concentration and postnatal age.

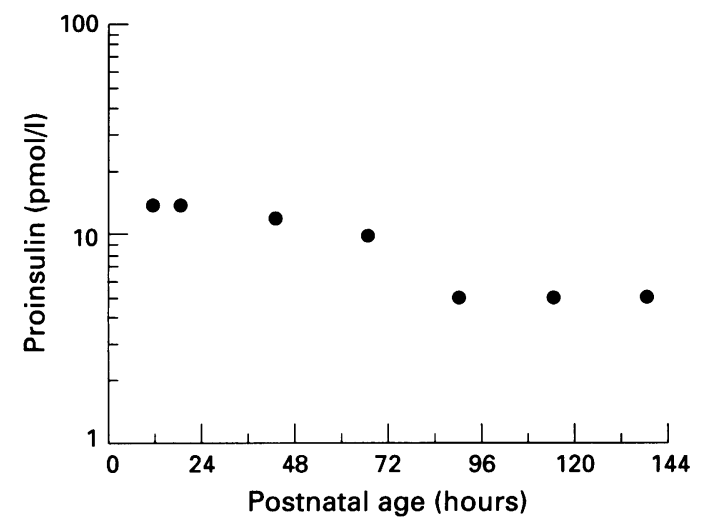

Figure 6 Correlation between proinsulin concentration and postnatal age for one baby.

infants in the present study had no evidence of metabolic or endocrine abnormalities and were not seriously systemically unwell. Therefore, we feel they are representative of other babies of similar gestational age. Unfortunately, we were not able to study a sufficient number of term babies to examine whether gestational immaturity is associated with high plasma insulin concentrations with respect to blood glucose concentrations, as suggested in the previous study. ${ }^{1}$ However, we feel that the data in this study are useful reference data and are more appropriate for use in the diagnosis of neonatal endocrine abnormalities than data taken from older children.

Thirdly, the theoretical implications of high circulating concentrations of proinsulin and other insulin propeptides must be considered. There are extensive data from adult studies to suggest that these propeptides have less glucoregulatory biological activity than insulin. ${ }^{6-8}$ However, these proinsulin-like molecules may have biological activity in fetal and early neonatal life and this may be related more to the regulation of growth than to glucoregulation. This is an interesting area for future investigation. The stimuli for proinsulin release may also differ from those for insulin secretion, or there may be heterogeneity among the $\beta$ cells with respect to the relative production of insulin or proinsulin-like molecules.

Fourthly, it is interesting to note that adult patients with disorders characterised by insulin resistance have high circulating concentrations of proinsulin and other insulin propeptides, although the proinsulin:insulin ratio may not differ from that of controls and is much lower than that found in our study $(11.8$ (SEM $3.6) \%$ for obese men and $31-154 \%$ in our study). The fasting proinsulin and 32-33 split proinsulin concentrations and the variation in concentrations in adult subjects with impaired glucose tolerance are less than those found in our study of neonates (adults: proinsulin 4.5 $(1 \cdot 0) \mathrm{pmol} / 1,32-33$ split proinsulin $7 \cdot 4(1 \cdot 3)$ pmol/1). ${ }^{9-12}$ It has been suggested that this is a consequence of pancreatic $\beta$ cell dysfunction, perhaps related to defective islet $\beta$ cell processing of proinsulin. Fetuses and preterm babies may exhibit the same type of $\beta$ cell function but this may have a specific role in fetal and neonatal development. ${ }^{13}$ The progressive 
reduction of neonatal circulating proinsulin concentrations may be a marker for changes in $\beta$ cell function with age. The concept of 'insulin resistance' may not be applicable to neonates, as it is for adults, as insulin has roles other than glucoregulation in fetal and early neonatal life and there may be additional stimuli, other than glucose, for its release.

Finally, this study is of interest in the light of recent studies which have linked low birthweight with subsequent $\beta$ cell dysfunction and impaired glucose tolerance. ${ }^{14-17}$ These studies suggest that there is an association between intrauterine nutrition and $\beta$ cell mass. Some preterm and small for gestational age (SGA) infants may have reduced $\beta$ cell mass, persistent differences in $\beta$ cell function, and insulin resistance which manifest in later life. These hypotheses should be explored by repeating the present study in small for gestational age infants, and by carrying out a prospective study of preterm and small for gestational age infants to determine when the adult pattern of insulin secretion develops, and whether those with prolonged proinsulin secretion are at risk of subsequent impaired glucose tolerance.

This study has shown that preterm neonates, particularly those who are immature in terms of postnatal and gestational age, have high circulating concentrations of insulin propeptides which may cross-react with insulin in the many radioimmunoassays in routine clinical use. It is important to use a highly specific insulin assay and neonatal reference data for neonatal investigations of pancreatic $\beta$ cell function. The relevance of high circulating concentrations of proinsulin and 32-33 split proinsulin in terms of biological activity and as markers of neonatal pancreatic maturation and future impaired glucose tolerance should be investigated further.

The financial support of the Medical Research Council, British Diabetic Association, and the Farley's/BAPM Research Award are acknowledged.
1 Hawdon JM, Aynsley-Green A, Alberti KGMM, Ward Platt MP. The role of pancreatic insulin secretion in neonatal MP. The role of pancreatic insulin secretion in neonatal
glucoregulation. I. Healthy term and preterm infants. Arch Dis Child 1993; 68: 274-9.

2 Soeldner JS, Slone D. Critical variables in the RIA of serum insulin using the double antibody system. Diabetes 1965 ; 14: 771-9.

3 Aynsley-Green A, Jenkins P, Trainer B, Heding L. Plasma proinsulin and C-peptide concentrations in children with hyperinsulinaemic hypoglycaemia. Acta Paediatrica Scand 1984; 73: 359-3.

4 Heding L, Persson B, Strangengberg M. B-cell function in newborn infants of diabetic mothers. Diabetol 1980; 19: 427-32.

5 Sobey WJ, Beer SF, Carrington CA, Clark PMS, Frank BH, Gray IP, et al. Sensitive and specific two-site immuno-
radiometric assays for human insulin, proinsulin, 65-66 split and 32-33 split proinsulins. Biochem $f$ 1989; 260: 535-41.

6 Revers RR, Henry R, Schmeiser L. The effects of biosynthetic human proinsulin on carbohydrate metabolism. Diabetes 1984; 33: 762-70.

7 Peavey DE, Brunner MR, Duckworth WC. Receptor binding and biological potency of several split form (conversion intermediates) of human proinsulin. Studies in cultured IM-9 lymphocytes and in vivo and in vitro in rats. F Biol Chem 1985; 260: 13989-94.

8 Glauber HS, Revers RR, Henry R, Schmeiser L, Wallace P, Kolterman OG, et al. In vivo deactivation of proinsulin action on glucose disposal and hepatic glucose production in normal man. Diabetes 1986; 35: 311-7.

9 Proudler AJ, Godsland IF, Stevenson JC. Insulin propeptides in conditions associated with insulin resistance in humans and their relevance to insulin measurements. Metabolism 1994; 43: 446-9.

10 Krentz AJ, Clark PM, Cox L, Nattrass $M$. Hyperproinsulinaemia in impaired glucose tolerance. Clin Sci 1993; 85: 97-100.

11 Davies MJ, Metcalfe J, Gray IP, Day JL, Hales CN. Insulin deficiency rather than hyperinsulinaemia in newly diagnosed Type 2 diabetes mellitus. Diabet Med 1993; 10: 305-12.

12 Davies MJ, Rayman G, Gray IP, Day JL, Hales CN. Insulin deficiency and increased plasma concentration of intact and 32-33 split proinsulin in subjects with impaired glucose tolerance. Diabet Med 1993; 10: 313-20.

13 Hales CN. Use of terminology related to fetal insulin secretion. Diabetol 1995; 38: 124.

14 Wilkin TJ. Early nutrition and diabetes mellitus. BMf 1993; 306: 283-4.

15 Hales CN, Barker DJP, Clark PMS, Cox LJ, Fall C, Osmond $\mathrm{C}$, et al. Fetal and infant growth and impaired glucose tolerance at age 64.BMf์ 1991; 303: 1019-22

16 McCance DR, Pettit DJ, Hanson RL, Jacobsson LTH, Knowler WC, Bennett PH. Birthweight and non-insulin dependent diabetes: thrifty genotype, thrifty phenotype, or surviving small baby genotype? $B M F$ 1994; 308 : 942-5.

17 Cook JTE, Levy JC, Page RCL, Shaw JAG, Hattersley AT, Turner RC. Association of low birthweight with $\beta$ cell function in the adult first degree relatives of noninsulin dependent diabetic subjects. BMF 1993; 306: 